\title{
ISSN 1823-626X
}

\section{Malaysian Journal of Fundamental and Applied Sciences}

\author{
available online at http://mjfas.ibnusina.utm.my
}

\section{Marangoni Mixed Convection Boundary Layer Flow in a Nanofluid}

\author{
Amirah Remeli ${ }^{1}$, Norihan Md Arifin²*, RoslindaNazar ${ }^{3}$, Fudziah Ismail² \\ ${ }^{1}$ Department of Mathematics,Universiti Putra Malaysia, 43400 UPM Serdang, Selangor, Malaysia, \\ ${ }^{2}$ Institute for Mathematical Research, Universiti Putra Malaysia, 43400 UPM Serdang, Selangor, Malaysia, \\ ${ }^{3}$ School of Mathematical Sciences, Faculty of Science \& Technology, UniversitiKebangsaanMalaysia, 43600 UKM Bangi, Selangor, Malaysia \\ Received 6 November 2012, Revised 22 February 2013, Accepted 28 February 2013, Available online 5 March 2013
}

\begin{abstract}
The problem of Marangoni mixed convection boundary layer flow and heat transfer that can be formed along the interface of two immiscible fluids in a nanofluid is studied using different types of nanoparticles. Numerical solutions of the similarity equations are obtained using the shooting method. Three types of metallic or nonmetallic nanoparticles, namely copper $(\mathrm{Cu})$, alumina $\left(\mathrm{Al}_{2} \mathrm{O}_{3}\right)$ and titania $\left(\mathrm{TiO}_{2}\right)$ are consideredby using a water-based fluid to investigate the effect of the solid volume fraction or nanoparticle volume fraction parameter $\varphi$ of the nanofluid. The influences of the interest parameters on the reduced velocity along the interface, velocity profiles as well as the reduced heat transfer at the interface and temperature profiles were presented in tables and figures.
\end{abstract}

| Marangoni mixed convection | boundary layer | heat transfer nanofluid |

( 2013 IbnuSina Institute. All rights reserved. http://dx.doi.org/10.11113/mjfas.v9n2.87

\section{INTRODUCTION}

Marangoni convection can be known as free surface of a viscous fluid is a source of convection flow if its surface tension is distributed non-uniformly (Thess et al [1]).Marangoni convection occurs when the surface tension of an interface (generally liquid-air) depends on the concentration of a species or on the temperature distribution. In the case of temperature dependence, the Marangoni effect is also called thermo-capillary convection. The Marangoni effect is of primary importance in the fields of welding, crystal growth and electron beam melting of metals. Marangoni boundary layers are also defined when their mathematical modeling dealt for fluids with a Prandtl number of order one (Napolitano. L. G. [2]). Some numerical studies on Marangoni convection in various geometries have been considered by Golia and Viviani [3], Christopher and Wang [4], Pop et al. [5], Chamka et al. [6], Magyari and The interest to study the antioxidant activity of the flavonoids has prompted us to synthesisenaringenin (1) and eriodictyol (2); two hydroxylatedflavanones abundant in grape fruit and lemon, respectively [5,6]. Chamka [7] and Hamid et al. [8].Nanofluid is a two-phase mixture in which the solid case with nano-sized particle as a main content. By dispersing solid particle in fluids (such as water, oil, or ethylene glycol), the nanofluid can be produce. Nanofluid is also can be defined as fluid containing nanometer sized particles which is called nanoparticles. Nanofluid also had attracted many researchers since decade ago. Arifin et al. [9] has studied a similarity solution for Marangoni boundary layer flow of a nonofluid. They discussed the existence of dual solutions inMarangoni convection boundary layer, which is consistent with the discussion given in Golia and Viviani [3] that for the constantexponent $\beta<0.5$, the solutions are not unique. Detailed results on the dual solutions in Marangoni boundary layer flow also can be found in Hamid et al. [10]. Further, the effects of suction and injection on Marangoni boundary layer flow in nanofluids have been discussed in Remeli et al. [11].

The aim of the present paper is to extend the Mixed Marangoni convection flow of a viscous and incompressible fluid (Newtonian fluid) first considered by Chamka et al [6] to the case of nanofluid using the model of Tiwari and Das [12]. Three different nanoparticles, namely copper ( $\mathrm{Cu}$ ), alumina $\left(\mathrm{Al}_{2} \mathrm{O}_{3}\right)$ and titania $\left(\mathrm{TiO}_{2}\right)$ are tested to investigate the effects of the nanoparticle volume fraction parameter $\phi$ of the nanofluid on the flow and heat transfer characteristics. The case of conventional or regular fluid ( $\phi=0$ ) with the Prandtl number $\operatorname{Pr}=0.7$ is also considered for comparison with the results reported by Chamka et al [6].

\section{MATHEMATICAL FORMULATION}

We consider the steady two-dimensional Marangoni boundary layer flow with buoyancy effects due to gravityand an external pressure gradient which occurs along an interface, $\mathrm{S}$ in a water based-nanofluid. We assume the 
gravity vector is aligned with the fluid interface, $\mathrm{S}$ and the flow field for two interfacing fluids are uncouple. The governing equation for the Marangoni boundary layer with water based nanofluid can be written as,

$$
\begin{aligned}
& \frac{\partial u}{\partial x}+\frac{\partial v}{\partial y}=0 \\
& u \frac{\partial u}{\partial x}+v \frac{\partial u}{\partial y}=u_{e} \frac{\partial u_{e}}{\partial x}+\frac{\mu_{n f}}{\rho_{n f}} \cdot \frac{\partial^{2} u}{\partial y^{2}}-\Gamma \lambda T \\
& u \frac{\partial T}{\partial x}+v \frac{\partial T}{\partial y}=\frac{1}{\operatorname{Pr}} \frac{k_{n f} / k_{f}}{\left(\rho C_{p}\right)_{n f} /\left(\rho C_{p}\right)_{f}} \frac{\partial^{2} T}{\partial y^{2}}
\end{aligned}
$$

subject to the boundary condition

$$
\begin{aligned}
& v=0, \quad T=T_{0}(x), \quad \frac{\mu_{n f}}{\mu_{f}} \frac{\partial u}{\partial y}=\frac{\partial T}{\partial x} \text { at } y=0 \\
& u=u_{e}(x), \quad T=T_{m} \quad \text { as } \quad y \rightarrow \infty
\end{aligned}
$$

where $u$ and $v$ are the velocity components along $x$ and $y$ axes, respectively, Tis the non-dimensional temperature of the nanofluid, $T_{0}(x)$ is the interface temperature distribution, $u_{e}(x)$ is the velocity of the external flow, $T_{m}$ is the constant temperature of the external flow, $\Gamma$ is a parameter that specifies the nature of buoyancy forces where $\Gamma=-1$ is for buoyancy-assisted Marangoni flow and $\Gamma=1$ is for buoyancy-opposed Marangoni flow, Pr is the Prandtl number, $\lambda$ is the Marangoni mixed convection parameter, $\mu_{n f}$ is the effective thermal conductivity of the nanofluid, $\rho_{n f}$ is the effective density of the nanofluid and $\alpha_{n f}$ is the thermal diffusivity of the nanofluid, $k_{n f}$ is the effective thermal conductivity of the nanofluid, which are given by, see Oztop and Abu Nada [13]

$$
\begin{aligned}
& \alpha_{n f}=\frac{k_{n f}}{\left(\rho C_{p}\right)_{n f}}, \rho_{n f}=(1-\phi) \rho_{f}+\phi \rho_{s}, \mu_{n f}=\frac{\mu_{f}}{(1-\phi)^{2.5}} \\
& \left(\rho C_{p}\right)_{n f}=(1-\phi)\left(\rho C_{p}\right)_{f}+\phi\left(\rho C_{p}\right)_{s} \\
& \frac{k_{n f}}{k_{f}}=\frac{\left(k_{s}+2 k_{f}\right)-2 \phi\left(k_{f}-k_{s}\right)}{\left(k_{s}+2 k_{f}\right)+\phi\left(k_{f}-k_{s}\right)}
\end{aligned}
$$

where $\phi$ is the solid volume fraction of the nanofluid or nanoparticles volume fraction, $\rho_{f}$ is the reference density of the fluid fraction, $\rho_{s}$ is the reference density of the solid fraction, $\mu_{f}$ is the viscosity of the fluid fraction, $k_{f}$ is the thermal conductivity of the fluid, $k_{s}$ is the thermal conductivity of the solid, $\left(\rho C_{p}\right)_{f}$ is the heat capacity of the fluid, $\left(\rho C_{p}\right)_{n f}$ is the heat capacity of the nanofluid and $\left(\rho C_{p}\right)_{s}$ is the effective heat capacity of the nanoparticle material.The last condition of (4) represents the
Marangonicoupling condition at the interface, having considered for the surface tension $\sigma$ the linear relation (see Chamkha et al. [6]),

$$
\sigma=\sigma_{0}\left[1-\gamma\left(T-T_{e}\right)\right](7)
$$

where $\gamma=-\left(1 / \sigma_{0}\right) \partial \sigma / \partial T>0$ is the temperature coefficient of surface tension and $\sigma_{0}$ is the constant surface tension at origin. The directions of the driving actions depend on the orientation of the temperature gradients in nanofluids, $\nabla T$ .Now, we look for a similarity solution of (1) - (3) subject the boundary conditions (4) have the following form:

$$
\begin{aligned}
& u(x, y)=u_{0} x^{m} f^{\prime}(\eta), \\
& v(x, y)=-\frac{1}{3} u_{0} l_{0} x^{m-p-1}\left[(m-p) f(\eta)+p \mu f^{\prime}(\eta)\right] \\
& T(x, y)=-T_{0} x^{n} g(\eta), \\
& \eta=x^{p} y / l_{0} \\
& u_{e}(x)=u_{0} x^{m}
\end{aligned}
$$

wherem, $n, p$ are constants and primes denote differentiation with respect to $\eta$, and $u_{0}, l_{0}, T_{0}$ are constant scale factors to be determined. The similarity solutions exist for $m=3, n=$ 5 and $p=1$. Using the similarity transformation (8), (2) (4) are transform into the following ordinary differential equations

$$
\begin{aligned}
& \frac{f^{\prime \prime \prime}}{(1-\phi)^{2.5}\left(1-\phi+\frac{\phi \rho_{s}}{\rho_{f}}\right)}-\left(\frac{3}{2}\right)\left(f^{\prime 2}-1\right)+f^{\prime} f^{\prime \prime}+\Gamma \lambda g=0 \\
& \frac{1}{\operatorname{Pr}} \frac{k_{n f} / k_{f}}{(1-\phi)+\phi\left[\left(\rho C_{p}\right)_{s} /\left(\rho C_{p}\right)_{f}\right]} g^{\prime \prime}-\frac{5}{2} f^{\prime} g+f g^{\prime}=0
\end{aligned}
$$

subject to the boundary condition, which now become

$$
\begin{aligned}
& f(0)=0, \quad \frac{1}{(1-\phi)^{2.5}} f^{\prime \prime}(0)=-1, \quad g(0)=1 \\
& f^{\prime}(\infty)=1, \quad g(\infty)=0
\end{aligned}
$$

\section{RESULTS \& DISCUSSION}

The nonlinear ordinary differential equation (9) and (10) and subject to boundary condition (11) were solved numerically using shooting method. We consider both flow cases which is buoyancy-opposed Marangoni flow $(\Gamma=1)$ and buoyancy-assitedMarangoni flow $(\Gamma=-1)$. Following Oztop and Abu Nada [13], we considered the range of nanoparticles fraction $\phi$ as $0 \leq \phi \leq 0.2$ as shown in Table 1 . The Prandtl number, Pr of the based fluid (water) is kept constant at $\operatorname{Pr}=6.2$. Table 2 shows the numerical values of 
the reduced interface velocity, $f^{\prime}(0)$ and the surface temperature gradient orheat transfer, $-g^{\prime}(0)$, for some values of the Prandtl number, Prwhen theMarangoni mixed convection $(\lambda=1)$ and the pressure gradient is absent.The comparisons are found to be in excellent agreement. Therefore, we are confident that thepresent results are accurate. Table 3 and Table 4 shows the value of interface velocity $f^{\prime}(0)$ and heat transfer $-g^{\prime}(0)$ for all three nanoparticles $\left(\mathrm{Cu}, \quad \mathrm{Al}_{2} \mathrm{O}_{3}, \mathrm{TiO}_{2}\right)$ when $\phi=0.1$ for buoyancy-opposed Marangoni flow and buoyancy-assisted Marangoni flow, respectively. One can see that the interface velocity, $f^{\prime}(0)$ and heat transfer $-g^{\prime}(0)$ decreases as the mixed convection parameter, $\lambda$ increases for favourable cases. While for opposing cases, as $\lambda$ increases, the interface velocity, $f^{\prime}(0)$ and heat transfer $-g^{\prime}(0)$ increase. Fig. 1 and 2 show the variation with mixed convection parameter $\lambda$ of the interface velocity $f^{\prime}(0)$ and heat transfer at the interface $-g^{\prime}(0)$ when $\phi=0.1$ with differenttype ofnanoparticles $\left(\mathrm{Cu}, \mathrm{Al}_{2} \mathrm{O}_{3}\right.$ and $\left.\mathrm{TiO}_{2}\right)$ and both buoyancy-opposed and buoyancy-assisted Marangoni flow cases. It is observed that the reduced value of thermal diffusivity leads to higher temperature gradients and, therefore, higher enhancements in heat transfer.

Table 1. Thermophysical properties of regular fluid and nanoparticles (Oztop and Abu-Nada [13]).

\begin{tabular}{ccccc}
\hline $\begin{array}{c}\text { Physical } \\
\text { properties }\end{array}$ & $\begin{array}{c}\text { Fluid } \\
\text { phase } \\
\text { (water) }\end{array}$ & $\mathrm{Cu}$ & $\mathrm{Al}_{2} \mathrm{O}_{3}$ & $\mathrm{TiO}_{2}$ \\
\hline$C_{p}(\mathrm{~J} / \mathrm{kgK})$ & 4179 & 385 & 765 & 686.2 \\
$\rho\left(\mathrm{KG} / \mathrm{m}^{3}\right)$ & 997.1 & 8933 & 3970 & 4250 \\
$k(\mathrm{~W} / \mathrm{mK})$ & 0.613 & 400 & 40 & 8.9538 \\
$\alpha \times 10^{7}\left(\mathrm{~m}^{2} / \mathrm{s}\right)$ & 1.47 & 1163.1 & 131.7 & 30.7 \\
$\beta \times 10^{-5}(1 / \mathrm{K})$ & 21 & 30.7 & 0.85 & 0.9 \\
\hline
\end{tabular}

Table 2. Comparison of the values of $f^{\prime}(0)$ and $-g^{\prime}(0)$ for some values of $\operatorname{Pr}$ and $\lambda=1$ for buoyancy-assited Marangoni flow

\begin{tabular}{ccccccc}
\hline Pr & \multicolumn{2}{c}{$\begin{array}{c}\text { Golia and } \\
\text { Viviani [3] }\end{array}$} & \multicolumn{2}{c}{ Chamka et al. [6] } & \multicolumn{2}{c}{ Present } \\
& $f^{\prime}(0)$ & $-g^{\prime}(0)$ & $f^{\prime}(0)$ & $-g^{\prime}(0)$ & $f^{\prime}(0)$ & $-g^{\prime}(0)$ \\
\hline 0.13 & 1.23 & 0.535 & 1.2311 & 0.5371 & 1.2309 & 0.5371 \\
0.25 & 1.196 & 0.762 & 1.1973 & 0.7627 & 1.1973 & 0.7632 \\
0.5 & 1.155 & 1.106 & 1.1556 & 1.1064 & 1.1556 & 1.1064 \\
1.0 & 1.111 & 1.599 & 1.1109 & 1.5996 & 1.1110 & 1.5997 \\
2.0 & 1.086 & 2.299 & 1.0686 & 2.3002 & 1.0689 & 2.3002 \\
5.0 & 1.022 & 3.687 & 1.0223 & 3.6860 & 1.0228 & 3.6860 \\
\hline
\end{tabular}

Table 3. Values of $f^{\prime}(0)$ and $-g^{\prime}(0)$ for some values of $\lambda$, $\operatorname{Pr}=6.2$ and $\phi=0.1$ with different nanoparticles for buoyancy-opposed $(\Gamma=1)$ Marangoni flow

\begin{tabular}{rrrrccc}
\hline$\lambda$ & \multicolumn{2}{c}{$\mathrm{Cu}$} & \multicolumn{2}{c}{$\mathrm{Al}_{2} \mathrm{O}_{3}$} & \multicolumn{2}{c}{$\mathrm{TiO}_{2}$} \\
& $f^{\prime}(0)$ & $-g^{\prime}(0)$ & $f^{\prime}(0)$ & $-g^{\prime}(0)$ & $f^{\prime}(0)$ & $-g^{\prime}(0)$ \\
\hline 0 & 1.2393 & 3.5013 & 1.3017 & 3.5924 & 1.2968 & 3.7104 \\
1 & 1.1366 & 3.3585 & 1.2191 & 3.4783 & 1.2149 & 3.5933 \\
2 & 1.0206 & 3.1898 & 1.1283 & 3.3488 & 1.1251 & 3.4605 \\
3 & 0.8838 & 2.9795 & 1.0265 & 3.1972 & 1.0243 & 3.3053 \\
4 & 0.7076 & 2.6855 & 0.9077 & 3.0112 & 0.9070 & 3.1152 \\
5 & 0.3071 & 1.8690 & 0.7581 & 2.7599 & 0.7599 & 2.8597 \\
\hline
\end{tabular}

Table 4. Values of $f^{\prime}(0)$ and $-g^{\prime}(0)$ for some values of $\lambda$, $\operatorname{Pr}=6.2$ and $\phi=0.1$ with different nanoparticles for buoyancy-assisted $(\Gamma=-1)$ Marangoni flow

\begin{tabular}{rrrrrrr}
\hline$\lambda$ & \multicolumn{2}{c}{$\mathrm{Cu}$} & \multicolumn{2}{c}{$\mathrm{Al}_{2} \mathrm{O}_{3}$} & \multicolumn{2}{c}{$\mathrm{TiO}_{2}$} \\
& $f^{\prime}(0)$ & $-g^{\prime}(0)$ & $f^{\prime}(0)$ & $-g^{\prime}(0)$ & $f^{\prime}(0)$ & $-g^{\prime}(0)$ \\
\hline 0 & 1.2393 & 3.5013 & 1.3017 & 3.5924 & 1.2968 & 3.7104 \\
1 & 1.3326 & 3.6262 & 1.3782 & 3.6948 & 1.3726 & 3.8156 \\
2 & 1.4186 & 3.7378 & 1.4497 & 3.7881 & 1.4434 & 3.9115 \\
3 & 1.4988 & 3.8392 & 1.5171 & 3.8741 & 1.5103 & 3.9998 \\
4 & 1.5743 & 3.9322 & 1.5810 & 3.9540 & 1.5737 & 4.0820 \\
5 & 1.6459 & 4.0185 & 1.6420 & 4.0287 & 1.6342 & 4.1588 \\
\hline
\end{tabular}

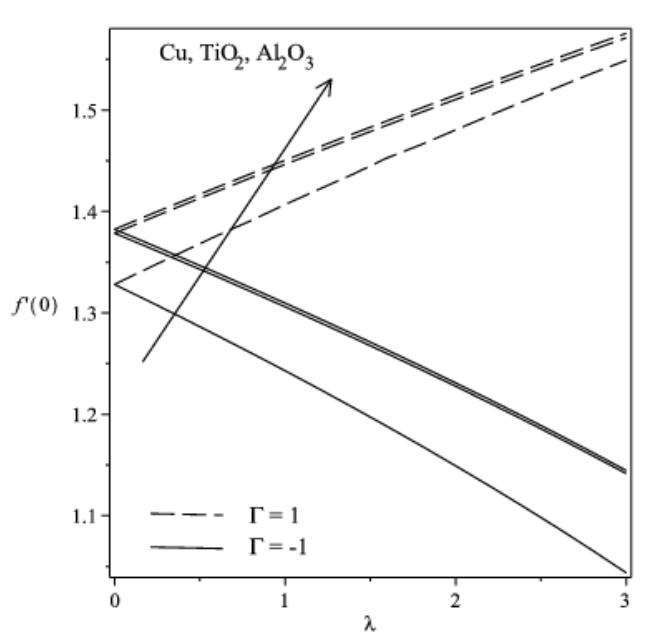

Fig. 1. Variations of $f^{\prime}(0)$ with $\lambda$ for different types of nanoparticles when $\phi=0.1$ for opposing $(\Gamma=1)$ and favourable $(\Gamma=-1)$ cases.

Nanoparticles with low thermal diffusivity, $\mathrm{TiO}_{2}$, have better enhancement on heat transfer compared to $\mathrm{Cu}$ and $\mathrm{Al}_{2} \mathrm{O}_{3}$ as shown in Fig. 3. It is worth mentioning that nanoparticle volume fraction $\phi$ is a key parameter for studying the effect of nanoparticles on flow fields and 
temperature distributions. More fluid is heated for higher values of nanoparticle volume fraction. Flow strength also increases with increasing of nanoparticle volume fraction. Figs. 3 to 6 show the effects of Marangoni mixed convection parameter $\lambda$ on the velocity and temperature profiles for the buoyancy-opposed and assisted Marangoni flow, respectively for $\mathrm{Cu}$ nanoparticles. It is seen that for buoyancy-opposed Marangoni flow case, both the velocity and temperature profiles decrease as $\phi$ increases, while for buoyancy-assisted Marangonifllow case the velocity profiles increase and the temperature profiles decrease with an increase of $\phi$. Furthermore, temperature profile (for buoyancy-opposed and assisted Marangoni flow cases) and velocity profiles (for buoyancy-assisted Marangoni flow) decrease as $\lambda$ increases. This is in agreement with the results reported by Chamka et al. [6].

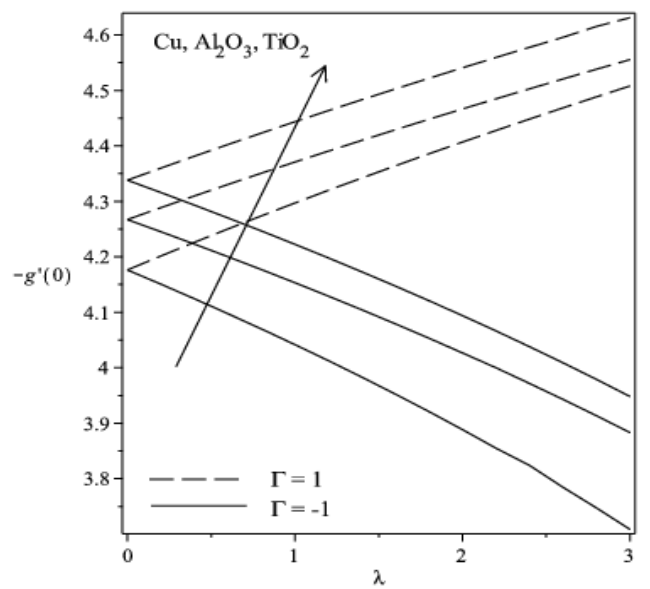

Fig. 2. Variations of $-g^{\prime}(0)$ with $\lambda$ for different types of nanoparticles when $\phi=0.1$ for opposing $(\Gamma=1)$ and favourable $(\Gamma=-1)$ cases.

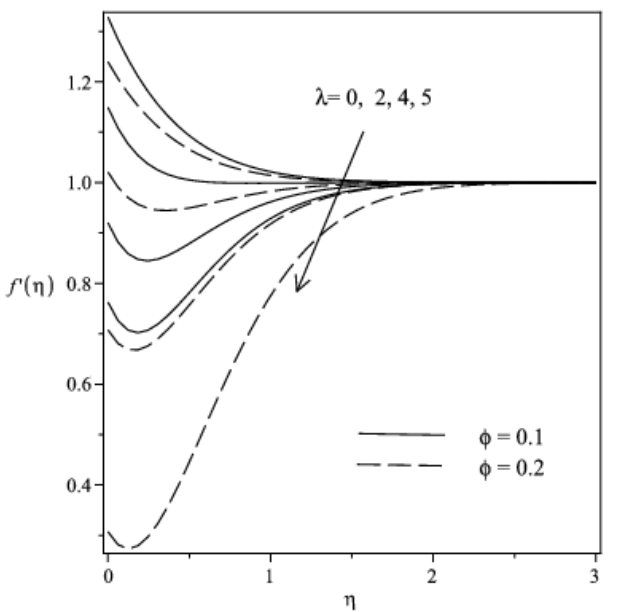

Fig. 3.Velocity profilesfor $\mathrm{Cu}$ nanoparticles with $\Gamma=-1$, $\phi=0.1$ and 0.2 and various $\lambda$

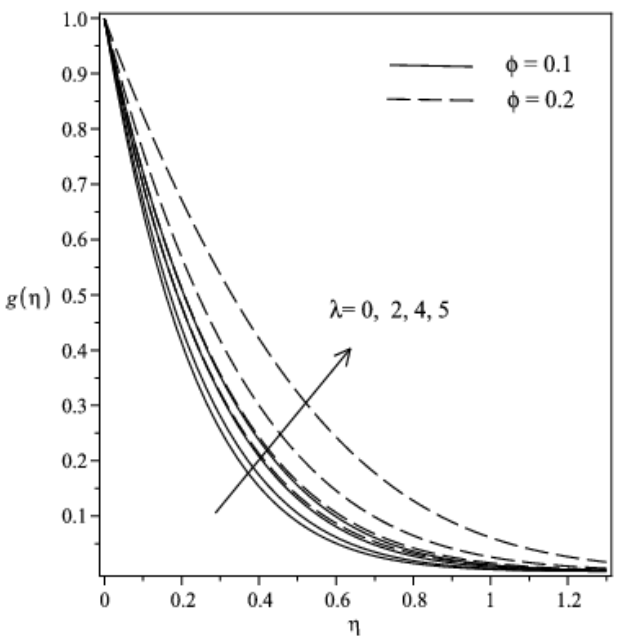

Fig. 4. Temperature profiles for $\mathrm{Cu}$ nanoparticles with $\Gamma=-1$, $\phi=0.1$ and 0.2 and various $\lambda$.

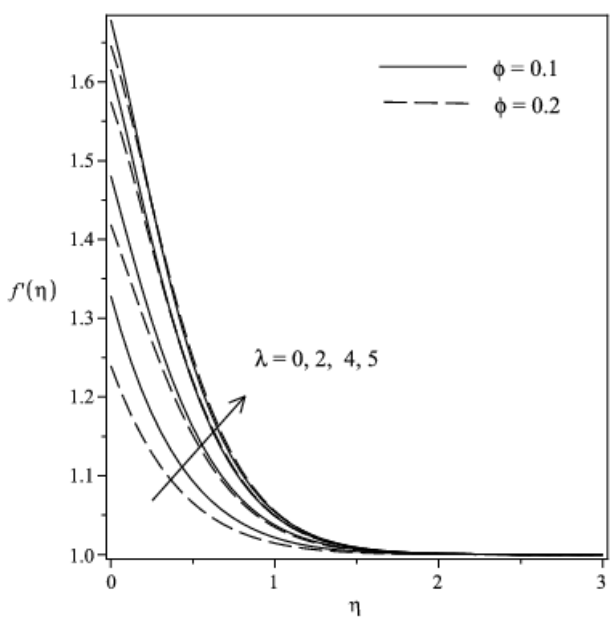

Fig. 5. Velocity profiles for $\mathrm{Cu}$ nanoparticles with $\Gamma=1$, $\phi=0.1$ and 0.2 and various $\lambda$

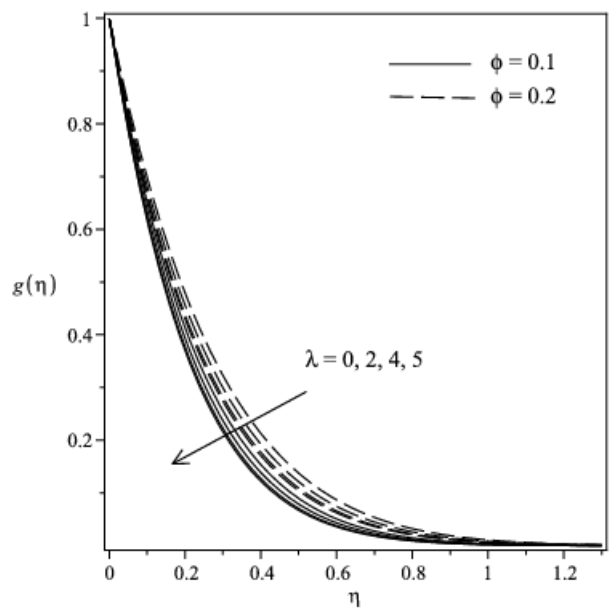

Fig. 6. Temperature profiles for Cu nanoparticles with $\Gamma=1$, $\phi=0.1$ and 0.2 and various $\lambda$ 


\section{CONCLUSION}

We have numerically studied the problem of steady coupled Marangoni mixed convection boundary layer flow in nanofluids. Three different types of nanoparticles, namely $\mathrm{Cu}, \mathrm{Al}_{2} \mathrm{O}_{3}$ and $\mathrm{TiO}_{2}$ are considered. The governing partial differential equations were transformed into a set of two nonlinear ordinary differential equation using similarity transformation and solved numerically using shooting method. The interface velocity $f^{\prime}(0)$, heat transfer $-g^{\prime}(0)$ as well as the velocity and temperature profiles for both buoyancy-opposed and buoyancy-assisted Marangoni flow cases are determined and discussed in detail. It is concluded that the Marangoni mixed convection parameter $\lambda$ and the nanoparticle volume fraction $\phi$ have a substantial effect on the flow and heat transfer characteristics.

\section{ACKNOWLEDGEMENT}

The authors gratefully acknowledgemed the financial support received in the form of a Research University Grant Scheme (RUGS) from Universiti Putra Malaysia.

\section{REFERENCES}

[1] A. Thess, D. Spirn, and B. Ttner, J. Fluid Mec.,331 (1996), 283 312.

[2] L. G. Napolitano,Annals of the New York Academy of Sciences,404 (2006), 278-298.

[3] C. Golia, and A. Viviani, Meccanica, 21 (1986), 200-204.

[4] D. M. Christophe,r and B. Wang, Int J Therm Sci., 40 (2001), 564570 .

[5] I.Pop, A. Postelnicu, and T. Grosan, Meccanica, 36 (2001), 555-571.

[6] A. J. Chamkha, I. Pop, and H.S. Takhar,Meccanica, 41 (2006), 219232.

[7] E. Magyari,and A.J. Chamkha, Int. J. Therm. Sci., 47 (2008), 848857.

[8] R. A. Hamid, N. M. Arifin, R. Nazar, and Ali F. M., Malaysian Journal of Mathematical Sciences 5 (1) (2011), 13 - 25.

[9] N. M. Arifin, R. Nazar, and I. Pop, Meccanica, 46 (4)(2011), 833843.

[10] R. A. Hamid,N.M. Arifin, R. Nazar, F.M. Ali, andI. Pop, Mathematical Problems in Engineering, 2011, 1-19.

[11] A. Remeli, N. M. Arifin, R. Nazar, F. Ismail, and I. Pop, World Applied Science Journal 17 (Special Issues in Applied Mathematics) (2012), 21-26.

[12] R. K. Tiwari, and M.K. Das, Int. J. Heat Mass Transfer, 50 (2007), 2002-2018.

[13] H. F. Oztop, and E. Abu-Nada, Int. J. Heat Fluid Flow, 29 (2008), 1326-1336. 